\title{
Pressure gradients calculated from PC-MRI, SPIV and CFD velocity data in a phantom model: comparison with catheter-based pressure measurement
}

\author{
Iman Khodarahmi ${ }^{1 *}$, Mostafa Shakeri ${ }^{1,2}$, Melanie Kotys-Traughber ${ }^{3}$, Stefan Fischer ${ }^{3}$, Keith M Sharp ${ }^{2}$, Amir Amini ${ }^{1}$ \\ From 15th Annual SCMR Scientific Sessions \\ Orlando, FL, USA. 2-5 February 2012
}

\section{Background}

Peripheral arterial disease (PAD) is a common manifestation of atherosclerosis and is defined as any pathologic process causing obstruction to blood flow in the arteries outside the heart; mainly the arteries supplying the lower extremities. Phase-contrast MRI (PC-MRI) provides a powerful and non-invasive method to acquire spatially registered blood velocity. The velocity field, then, can be used to derive other clinically useful hemodynamic parameters, such as blood pressure gradients.

\section{Methods}

Herein, pressure gradient across an axisymmetric Gaussian-shaped $87 \%$ area stenosis phantom was estimated by solving the pressure-Poisson equation (PPE). The velocity field needed to solve the pressure equation was obtained using PC-MRI and Stereoscopic Particle Image Velocimetry (SPIV). Steady flow rate of $46.9 \mathrm{ml} / \mathrm{s}$, corresponding to an inlet Reynolds number of 160, was used which mimics the Reynolds number of human common iliac artery. Sagittal PC-MRI images were acquired using a standard 2D phase contrast sequence with Cartesian read-out, through-plane velocity encoding, and velocity compensation in all three directions on a $3 \mathrm{~T} \mathrm{TX}$ Achieva Philips MRI scanner with slice thickness $=2$ $\mathrm{mm}$, resolution $=1 \times 1 \mathrm{~mm}, \mathrm{TE} / \mathrm{TR}=3.0 / 4.0 \mathrm{~ms}$, field of view $=192 \times 64 \mathrm{~mm}$, and velocity encoding $($ Venc $)=$ $120 \mathrm{~cm} / \mathrm{s}$. For SPIV purposes, a 532-nm laser light sheet was passed parallel to the axis of the phantom to illuminate the flowing fluorescent particles (Fig. 1). A set of

Electrical Engineering, University of Louisville, Louisville, KY, USA Full list of author information is available at the end of the article image pairs were captured using two cameras looking at the phantom at different angles and the fluid velocity was extracted using a cross-correlation scheme, yielding a nominal spatial resolution of $0.168 \mathrm{~mm}$ for the velocity data.

Computational Fluid Dynamics (CFD) simulation of the same flow was performed on the same geometry using the CFD software package Fluent 12.1 based on a finite volume scheme.

\section{Results}

The results of the PPE solution using the PC-MRI and SPIV velocity data are shown in Fig 2.

The Poisson equation was also solved using the CFD velocities, regridded to a rectangular mesh of the same grid resolution as PC-MRI. The pressure distribution obtained directly from the Fluent software is also shown for comparison. As shown in figure 2, good agreement exits between pressures calculated from different methods.

\section{Conclusions}

Pressure gradients calculated from PC-MRI data is comparable with those obtained from other experimental and numerical methods. Direct pressure measurement using two simultaneous catheters placed proximal and distal to the stenosis is currently under investigation and will be added as the ground truth to the discussed methods.

\section{Funding}

This work was supported in part by the National Science Foundation under Grant 0730467 and by an 
a

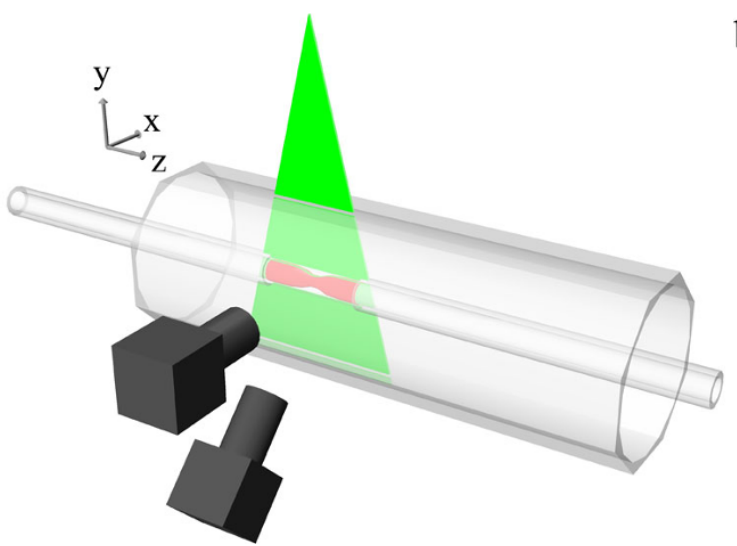

b

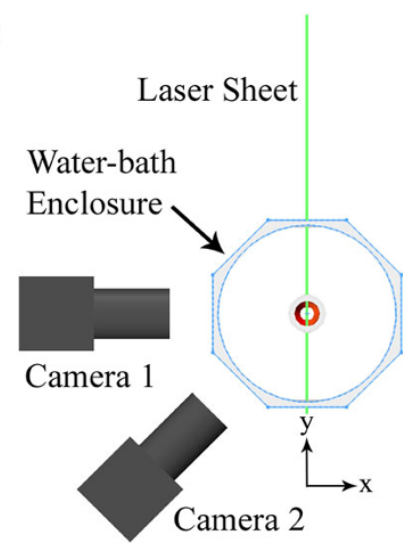

Figure 1 Schematic side view (a) and isometric view (b) of the SPIV apparatus.

a

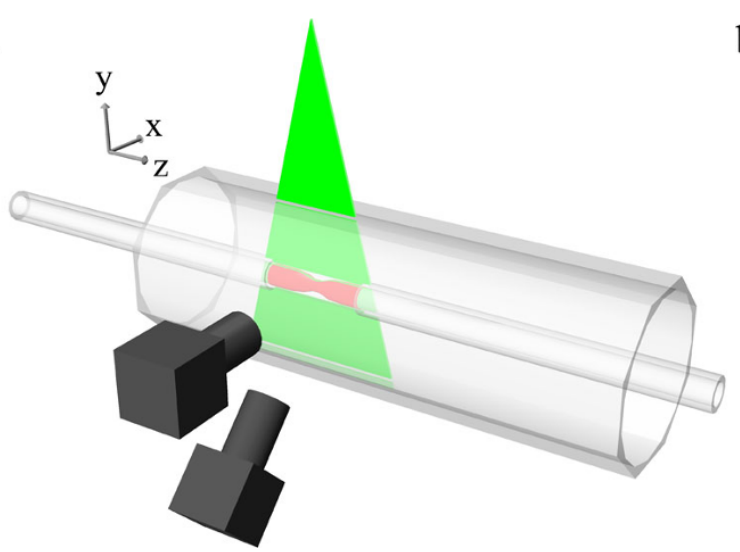

b Laser Sheet

Water-bath Enclosure

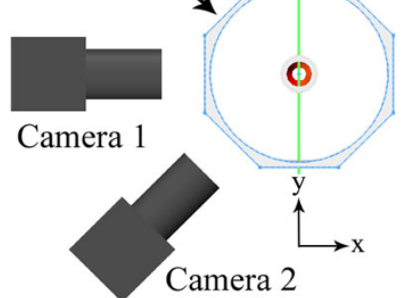

Figure 2 Pressure profiles along the centerline of the phantom calculated from different methods.

innovative grant from the Clinical and Translational

Research Program of the University of Louisville.

\section{Author details}

${ }^{1}$ Electrical Engineering, University of Louisville, Louisville, KY, USA.

${ }^{2}$ Mechanical Engineering, Univeristy of Louisville, Louisville, KY, USA. ${ }^{3} \mathrm{MR}$

Research, Philips Healthcare, Cleveland, OH, USA.

Published: 1 February 2012

doi:10.1186/1532-429X-14-S1-W34

Cite this article as: Khodarahmi et al.: Pressure gradients calculated from PC-MRI, SPIV and CFD velocity data in a phantom model: comparison with catheter-based pressure measurement. Journal of Cardiovascular Magnetic Resonance 2012 14(Suppl 1):W34.

\section{Submit your next manuscript to BioMed Central} and take full advantage of:

- Convenient online submission

- Thorough peer review

- No space constraints or color figure charges

- Immediate publication on acceptance

- Inclusion in PubMed, CAS, Scopus and Google Scholar

- Research which is freely available for redistribution

Submit your manuscript at www.biomedcentral.com/submit 